\title{
Nódulos de Aschoff e fibrose miocárdica em músculo papilar do ventrículo esquerdo
}

\author{
Lurildo R Saraiva, Gordano Bruno Parente, Vtal Lira
}

Pernambuco, PE

Mulher de 19 anos, com renda familiar mensal per capita inferior a $\mathrm{R} \$ 60,00$, apresentou insuficiência cardíaca atribuída a cardite reumática aguda. O exame físico revelou paciente pálida, dispnéica, com sinais de desnutrição. O índice de massa corpórea foi $18,2 \mathrm{~kg} / \mathrm{m}^{2}$. A semiologia do coração revelou ritmo de galope protodiastólico, e intenso sopro sistólico de insuficiência da valva mitral. O eletrocardiograma demonstrou aumento do intervalo PR. O ecocardiograma evidenciou diâmetro sistólico do átrio esquerdo alcançou $8,5 \mathrm{~cm}$, diâmetro diastólico do ventrículo esquerdo $7,3 \mathrm{~cm}$. A fração de ejeção do ventrículo esquerdo foi $52 \%$. A dosagem plasmática de anti-estreptolisina O foi de 298 U Todd

Recebeu tratamento com o emprego de diuréticos e vasodilatadores, $70 \mathrm{mg}$ diários de prednisona. A dose de prednisona administrada foi diminuída progressivamente no decorrer de 90 dias. Foi também administrada quinzenalmente a penicilina benzatina. A paciente permaneceu com palidez, dispnéia de esforço e idêntica semiologia cardíaca. A reavaliação ecocardiográfica na evolução demonstrou discreta redução dos valores de diâmetros diastólicos. O diâmetro diastólico do átrio esquerdo foi $6,8 \mathrm{~cm}$, o diâmetro diastólico do ventrículo esquerdo $7,1 \mathrm{~cm}$. A fração de ejeção do ventrículo normalizou-se (65\%).

Foi indicado o tratamento cirúrgico da insuficiência mitral. A paciente foi submetida à troca de valva mitral por bioprótese. O estudo histológico do fragmento de músculo papilar do ventrículo é apresentado nas figuras 1 e 2 .

\section{Comentários}

Em Pernambuco, a doença reumática exibe formas muito graves na população carente. A concomitância de achados histopatológicos típicos de fase aguda da doença reumática (fig. 1) com achados histológicos da fase crônica (fig. 2) indica tratar-se de surto agudo sobre coração previamente lesado pela doença. Evidencia ainda a perenidade da estimulação inflamatória, desencadeada por estrepto-

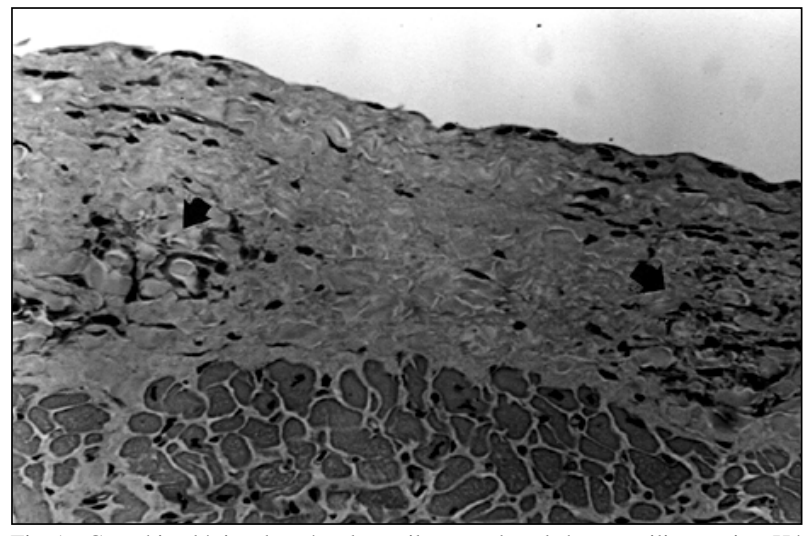

Fig. 1 - Corte histológico do músculo papilar, corado pela hematoxilina-eosina. Há espessamento endocárdico e dois nódulos de Aschoff em fase proliferativa (setas). (aumento original $400 \mathrm{x}$ )

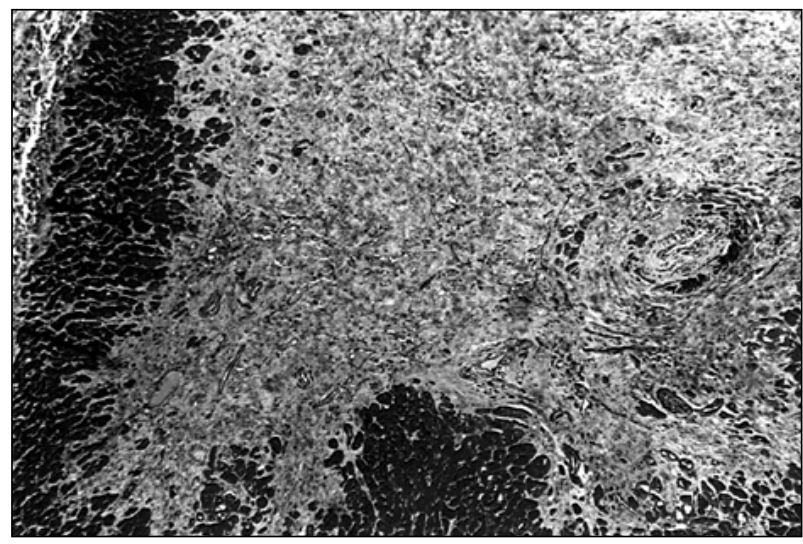

Fig. 2 - Corte histológico do miocárdio com intensa fibrose em placa, demonstrada pelas áreas coradas em azul, além de fibrose intersticial e perivascular, acompanhada de neoformação vascular. (Tricrômico de Mallory - aumento original 210x).

coccia silenciosa, a julgar pelo intenso dano tecidual cardíaco. Além disso, justifica a dificuldade no controle da moléstia pelo uso tradicional do corticosteróide. 